\title{
Optimalisasi Jumlah Bus Trans Metro Pekanbaru pada Trayek Pandau Pelita Pantai
}

\author{
Teguh Kurniawan ${ }^{1}$, Winayati ${ }^{2}$, Fadrizal Lubis $\mathrm{F}^{3}$. \\ Program Studi Teknik Sipil, Fakultas Teknik, Universitas Lancang Kuning \\ Jl. Yos Sudarso km. 8 Rumbai, Pekanbaru, Telp. (0761) 52324 \\ Email:Teguhkurniawan255@gmail.com,winayati@unilak.ac.id, fadrizal@unilak.ac.id
}

\begin{abstract}
ABSTRAK
Pekanbaru termasuk kategori pertumbuhan penduduknya tertinggi di Provinsi Riau, menurut Dinas Kependudukan Dan Catatan Sipil Kota Pekanbaru tahun 2015 penduduk Pekanbaru mengalami pertumbuhan sebesar 7,43\% Pertahun. Trayek pandau-pelita pantai merupakan trayek yang paling diminati oleh masyarakat Kota Pekanbaru, berdasarkan data yang didapat dari Dinas Perhubungan Kota Pekanbaru tahun 2017 jumlah penumpang pada trayek pandau-pelita pantai rata -rata 289 orang perhari perkendaraan, atau load faktor nya hanya 52,26\% sedangkan load faktor yang ditetapkan oleh Surat Keputusan Direktorat Jenderal Perhubungan Darat No. 687 tahun 2002 minimal $70 \%$ Bus Trans Metro Pekanbaru (TMP) merupakan usaha Pemerintah untuk mengakomodasi meningkatnya jumlah tata guna lahan dan pergerakan penumpang. Penelitian ini dilakukan pada trayek Pandau- Pelita Pantai dengan panjang lintasa 14,9 Km dengan tujuan untuk mengetahui jumlah bus yang optimal pada trayek Pandau- Pelita Pantai. Analisis yang digunakan pada penelitian ini mengacu Keputusan Direktur Jendral Perhubungan Darat 2002. Sebelum melakukan analisis terlebih dahulu dilakukan survei lapangan untuk mengambil data jumlah penumpang perjam, jarak dari Pandau ke Pelita Pantai dan waktu perjalanan dari Pandau ke Pelita Pantai. Dari hasil analisis yang dilakukan didapat jumlah bus yang optimal pada trayek Pandau- Pelita Pantai 11 unit dengan waktu tunggu 10 menit, dan biaya operasional kendaraan (BOK) Rp. 66.023 /km, Rp. 13.774.535 /hari, Rp. 413.236.062 /bulan, Rp. 4.958.832.752/tahun.
\end{abstract}

Kata kunci : Optimalisasi, Trans Metro pekanbaru

\begin{abstract}
Pekanbaru is the highest population growth category in Riau Province, according to Population and Civil Registration Office Pekanbaru City in 2015 Pekanbaru population growth of 7.43\% / year. The trajectory of coastal Pandau-Pelita Pantai the most preferred route by the people of Pekanbaru City, based on data obtained from the Department of Transportation Pekanbaru City in 2017 the number of passengers on the route PandauPelita Pantai shelves average 289 people/ day riding, or load factor is only $52.26 \%$ while the load factor determined by the Decree of the Directorate General of Land Transportation no. 687 year 2002 at least $70 \%$ Bus Trans Metro Pekanbaru (TMP) is a Government effort to accommodate the increasing number of land use and passenger movement. This research was conducted on the route of Pandau-Pelita Pantai with a $14.9 \mathrm{~km}$ long lintasan in order to know the optimal number of buses on the Pandau-Pelita Pantai route. The analysis used in this study refers to the Decree of the Director General of Land Transportation 2002. Before conducting the first analysis conducted field survey to take data of the number of passengers per hour, the distance from Pandau to Pelita Beach and travel time from Pandau to Pelita- pantai. From the analysis, the optimal number of buses in the route of Pandau-Pelita Pantai 11 units with waiting time of 10 minutes, and the operational cost of the vehicle (BOK) Rp. 66,023 / km, Rp. 13,774,535 / day, Rp. 413.236.062 / month, Rp. 4,958,832,752 / year.
\end{abstract}

Keywords: Optimization, Trans Metro Pekanbaru

Kurniawan, Optimalisasi Jumlah Bus Trans Metro Pekanbaru pada Trayek Pandau Pelita Pantai 


\section{PENDAHULUAN}

Kota pekanbaru adalah Ibu Kota Provinsi Riau, Kota ini merupakan Kota perdagangan dan pendidikan. Termasuk sebagai Kota yang tingkat pertumbuhan penduduk nya tinggi, menurut Dinas Kependudukan Dan Catatan Sipil Kota Pekanbaru tahun 2015, penduduk Pekanbaru mengalami pertumbuhan sebesar 7,43 persen per tahun yang termasuk kategori pertumbuhan tertinggi di Provinsi Riau. Sehingga aktivitas penduduk juga semakin meningkat seperti belanja, ke kantor, ke sekolah dan akan membutukan mobilitas yang tinggi..

Trans Metro Pekanbaru (TMP) merupakan sarana angkutan umum massal yang telah beroperasi sejak tahun 2009, penyediaan Trans Metro Pekanbaru (TMP) merupakan usaha pemerintah untuk mengakomodasi meningkat nya jumlah tata guna lahan dan pergerakan penumpang, namun pada kenyataan nya bus trans metro pekanbaru kurang di minati masyarakat karena rutenya masih terbatas,selain itu pertumbuhan kendaraan pribadi yang meningkat. Serta jasa angkutan online lebih di minati masyarakat karena lebih praktis, nyaman dan bisa antar jemput ke tujuan, dengan harga yang relatif murah dari pada angkutan konvensional.

Berdasarkan data yang didapat dari Dinas Perhubungan Kota Pekanbaru tahun 2017 trayek pandau-pelita pantai merupakan trayek yang paling banyak penumpang di banding trayek-trayek lainnya dan bus yang beroperasi pada trayek pandau - pelita pantai adalah bus besar lantai tunggal dengan kapasitas kendaraan 79 orang, jumlah penumpang pada trayek pandau-pelita pantai rata -rata 289 orang perhari perkendaraan, atau load factor nya hanya $52,26 \%$ sedangkan load factor yang ditetapkan oleh Surat Keputusan Direktorat Jenderal Perhubungan
Darat No. 687 tahun 2002 minimal 70 \%. Maka diperlukan suatu kajian untuk mengetahui kebutuhan jumlah bus Trans Metro Pekanbaru (TMP) yang optimal pada trayek pandau - pelita pantai. Saat ini trayek pandau - pelita pantai mengoperasikan sebanyak 12 unit armada Trans Metro Pekanbaru (Dinas Perhubungan Kota Pekanbaru tahun 2018)

\section{METODE PENELITIAN}

Dalam suatu analisa maupun perencanaan transportasi, pengumpulan data merupakan salah satu tahapan yang sangat penting, tujuan dari tahap pengumpulan data dalam penelitian ini adalah untuk mendapatkan seluruh data mentah yang akan digunakan dalam analisis, data yang dikumpul kan dalam penelitian ini adalah data primer dan data sekunder, dan sebelum melakukan pengumpulan data secara lengkap, dilakukan survei pendahuluan yang bertujuan untuk mengetahui karakter pergerakan bus trans metro pekanbaru trayek pandai pelita pantai, dan untuk menentukan metode survei data primer yang efisien, yang akan dijadikan acuan dasar dalam penentuan waktu survei. Berdasarkan hasil survei pendahuluan yang dilakukan, maka pengambilan data survei lapangan dilakukan selama 7 (Tujuh) hari sabtu tanggal 31 Maret 2018 sampai jum'at tanggal 6 April 2018.

1. Data Primer

Data primer adalah data yang diperoleh dari survei dilokasi penelitian. Survei yang dilakukan tersebut akan memperoleh data-data yang nyata sesuai kondisi dilapangan .Adapun data-data dilapangan yang dikumpulkan meliputi:

a. Waktu perjalanan dari pandau ke pelita pantai

b. Waktu perjalanan dari pelita pantai ke pandau

c. Data jumlah penumpang per jam 
d. Jarak dari pandau ke pelita pantai

2. Data Skunder

Pengumpulan data sekunder diperoleh dari instansi terkait, dalam penelitian ini data sekunder berasal dari Dinas Perhubungan Kota Pekanbaru. Adapun data sekunder yang dibutuhkan untuk penelitian ini meliputi:

a. Data Jumlah penumpang tahun 2017

b. Jumlah bus yang beroperasi

Survei dilakukan untuk mengumpulkan data primer berupa waktu perjalanan bus dari pandau ke pelita pantai, perjalanan bus dari pelita pantai ke pandau dan menghitung jumlah penumpang perjam. Metode pelaksanaan pengambilan data pada saat survei adalah sebagai berikut:

1. Data waktu perjalanan bus dari pandau ke pelita pantai maupun dari pelita pantai ke pandau pengambilan waktu perjalanan dengan stopwatch, dengan cara mengikuti bus dan mencatat waktu perjalanan.

2. Pengambilan data jumlah penumpang surveyor berjumlah 12 orang atau 1 orang perkendaraan dengan cara mengikuti bus trans metro pekanbaru dan menghitung jumlah penumpang perjam di dalam bus.

3. Pengambilan jarak dari pandau ke pelita pantai menggunakan alat GPS, dengan cara mengambil titik koordinat di pandau (titik awal) kemudian tracking dan mengambil titik koordinat di pelita pantai (titik tujuan)

\section{Alat Yang Digunakan}

1. Stopwatch untuk menghitung waktu perjalanan bus

2. Clipboard untuk alas menulis

3. Formulir survei
4. Alat tulis

\section{Bagan Alir Penelitian}

Bagan alir penelitian mengenai optimalisasi jumlah bus dapat dilihat pada gambar 1 .

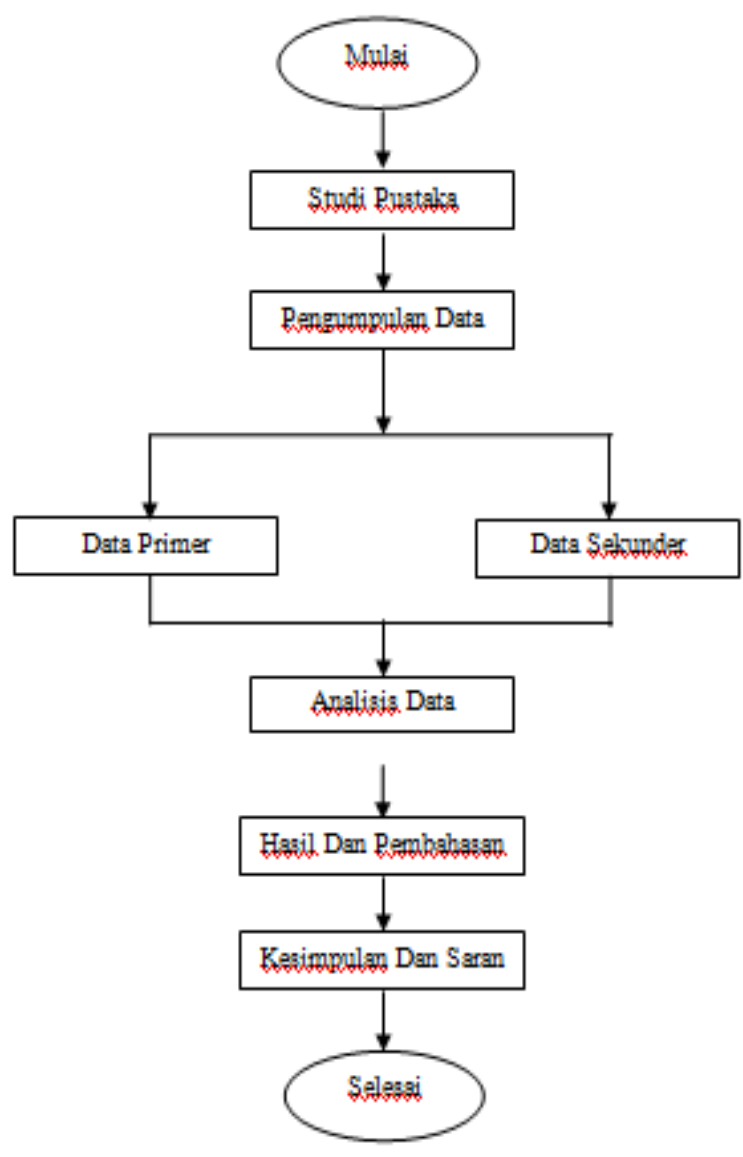

Gambar 1. Diagram alir pembuatan bata ringan

\section{HASIL DAN PEMBAHASAN}

\section{Data Primer}

Data hasil survei jumlah penumpang bus Trans Metro Pekanbaru trayek 1 pandau- pelita pantai yang dilakukan selama tujuh hari yakni dimulai pada hari sabtu tanggal 31 maret 2018 sampai hari jum'at tanggal 6 april 2018. 
Table 1. data jumlah penumpang maksimum trayek pandau pelita pantai pada hari selasa tanggal 3 april 2018

\begin{tabular}{|c|c|c|c|c|c|c|c|c|c|c|c|c|c|}
\hline \multirow{2}{*}{ Wakt } & \multicolumn{12}{|c|}{ Elan Bua Tran Marto Rokanban } & \multirow{2}{*}{ lelat } \\
\hline & $t$ & 2 & 3 & 4 & 5 & 6 & 7 & 8 & 9 & 50 & 11 & 12 & \\
\hline 0600.0700 & 22 & 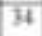 & 26 & $3 i$ & 25 & 29 & 10 & is & 14 & 11 & II & 22 & 257 \\
\hline $0700-0600$ & Is & 31 & 36 & 25 & 20 & 22 & 27 & 15 & 23 & 8 & 20 & 30 & 305 \\
\hline $100-5000$ & 22 & is & 10 & 21 & 29 & 21 & 12 & 10 & 23 & 26 & 20 & 27 & 220 \\
\hline $0900-1000$ & 17 & 20 & 13 & 19 & 21 & 21 & BS & $\pi$ & 22 & 22 & 14 & 16 & 216 \\
\hline $1000 \cdot 11.00$ & 12 & it & 10 & 16 & 20 & 13 & 23 & 19 & 23 & 15 & 17 & 18 & 205 \\
\hline $1200 \cdot 1200$ & II) & 19 & 26 & 20 & (2) & $2 \pi$ & if & Ij & 21 & 22 & 2) & 19 & 257 \\
\hline $1200 \cdot 1300$ & 23 & 19 & 26 & 13 & 21 & 17 & is & 25 & 21 & 16 & 21 & 22 & 212 \\
\hline $1300 \cdot 1400$ & is & 24 & 20 & 31 & 28 & 19 & 20 & 25 & 22 & 25 & 33 & 19 & 24 \\
\hline $1400-1500$ & 24 & 1) & 25 & 29 & 30 & 21 & 19 & 20 & 26 & B5 & 21 & 18 & 287 \\
\hline $1500-1600$ & is & 20 & 17 & 21 & 28 & 16 & 23 & 25 & 19 & 23 & 27 & 21 & 262 \\
\hline $1600-17.00$ & 2 & 20 & 33 & 23 & 21 & 27 & 20 & 19 & 20 & 51 & 26 & 20 & 239 \\
\hline $1700-11.00$ & 36 & 34 & 2 & 211 & 21 & 19 & 31 & 37 & 32 & 23 & 31 & 29 & 734 \\
\hline $15.00-1900$ & 23 & is & 15 & 27 & 22 & 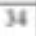 & 21 & 20 & 36 & 28 & 25 & 20 & 259 \\
\hline
\end{tabular}

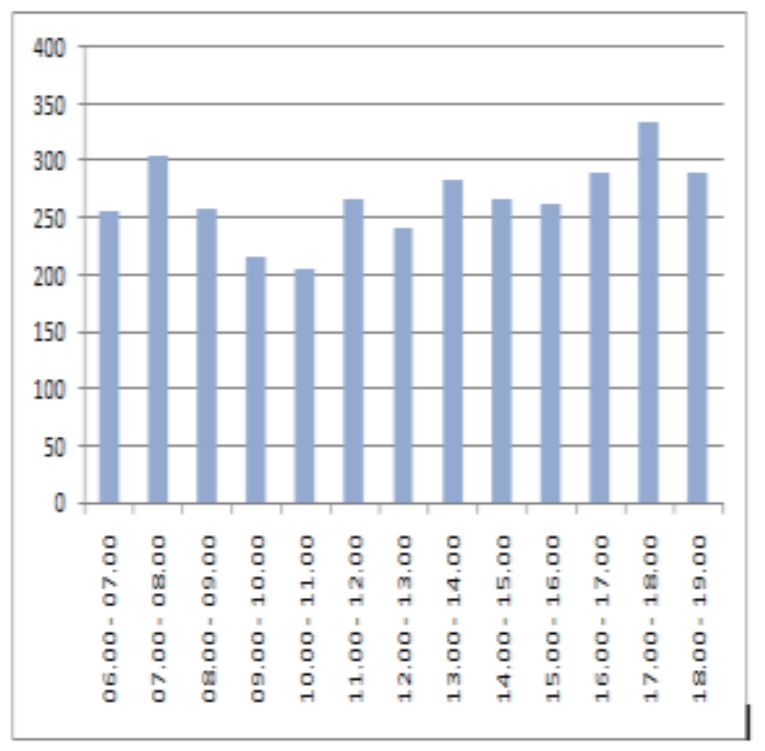

Gambar 2. Grafik hasil survey jumlah penumpang Trans Metro Pekanbaru (Sumber: data hasil survei, 2018)

\section{Data waktu tempuh}

Waktu yang dibutukan oleh kendaraan untuk melewati ruas jalan yang diamati, termasuk waktu berhenti untuk menaikan/ menurunkan penumpang dan perlambatan karena hambatan.
Tabel 2. Data waktu tempuh bus

\begin{tabular}{|c|c|c|}
\hline \multirow{2}{*}{ No Bus } & \multicolumn{2}{|c|}{ Waktu Tempuh ( Menit) } \\
\cline { 2 - 3 } & $\begin{array}{c}\text { Pandau - pelita } \\
\text { pantai }\end{array}$ & $\begin{array}{c}\text { Pelita pantai - } \\
\text { pandau }\end{array}$ \\
\hline 29 & 50 & 45 \\
\hline 10 & 40 & 50 \\
\hline 52 & 45 & 38 \\
\hline 51 & 45 & 50 \\
\hline 31 & 48 & 51 \\
\hline 12 & 45 & 49 \\
\hline 54 & 47 & 51 \\
\hline 36 & 46 & 59 \\
\hline 35 & 52 & 39 \\
\hline 47 & 58 & 40 \\
\hline 48 & 51 & 48 \\
\hline 49 & 49 & 39 \\
\hline Rata-rata & 48 & 46.583 \\
\hline
\end{tabular}

(sumber: data hasil survei, 2018)

\section{Analisis waktu sirkulasi}

Untuk mendapatkan waktu sirkulasi dapat digunakan persamaan 3.1, dimana $\sigma \mathrm{AB}$ dan $\sigma \mathrm{BA}$ adalah waktu deviasi dari A ke B sebesar 5\%, dan TTA dan TTB sebesar $10 \%$ (berdasarkan Surat Keputusan Direktorat Jenderal Perhubungan Darat No. 687 tahun 2002) maka:

$$
\begin{aligned}
\mathrm{CT} \text { ABA }= & (\mathrm{TAB}+\mathrm{TBA})+(\sigma \mathrm{AB}+\sigma \mathrm{BA})+ \\
& (\mathrm{TTA}+\mathrm{TTB}) \\
= & (48+46,583)+((5 \% \times 48)+(5 \% \mathrm{x} \\
& 46.583))+((10 \% \times 48)+(10 \% \mathrm{x} \\
& 46.583)) \\
= & 108,771 \text { menit }
\end{aligned}
$$

Dari perhitungan diatas didapat waktu sirkulasi sebesar 108,771 menit atau 1,813 jam yang dibutuhkan bus, Pandau menuju pelita pantai dan kembali ke pandau. Waktu tersebut memenuhi ketentuan dari Dirjen perhubungan darat yaitu maksimum 3 jam.

\section{Waktu antara kendaraan}


Untuk menganalisis waktu antara kendaraan digunakan rumus 3.2, dimana LF minimal $70 \%$ sesuai Surat Keputusan Direktorat Jenderal Perhubungan Darat No. 687 tahun 2002 maka:

$$
\begin{gathered}
H=\frac{60 . C \cdot L F}{P} \\
H=\frac{60 \times 79 \times 70 \%}{334} \\
H=9,934 \text { menit }
\end{gathered}
$$

Dari hasil perhitungan waktu antara kendaraan (headway) di gunakan 9,934 menit, waktu tersebut memenuhi standar Dirjen Perhubungan Darat tahun 2002 yaitu 5-10 menit.

\section{Jumlah armada perwaktu sirkulasi}

1. Perconaan 1

Untuk mengetahui jumlah armada perwaktu sirkulasi digunakan rumus dimana nilai $\mathrm{H}$ (headway) digunakan sebesar 9,934 menit maka:

$$
\begin{aligned}
& \mathrm{K}=\frac{\mathrm{CTABA}}{\mathrm{HxfA}} \\
& \mathrm{K}=\frac{108,771}{9,934 \times 100 \%} \\
& \mathrm{~K}=10,949=11 \text { unit armada }
\end{aligned}
$$

Dari hasil perhitungan jumlah armada perwaktu sirkulasi didapatkan jumlah armada 11 unit, dengan waktu tunggu sebesar 9,934 menit tersebut memenuhi standar Dirjen Perhubungan Darat tahun 2002 yaitu 510 menit.

2. Perconaan 2
Untuk perbandingan dicoba menggunakan 10 unit armada maka:

$$
\begin{aligned}
& \mathrm{K}=\frac{\text { CTABA }}{\mathrm{HxfA}} \\
& 10=\frac{108,771}{\mathrm{Hx} 100 \%} \\
& \mathrm{H}=\frac{108,771}{10}
\end{aligned}
$$

$$
\mathrm{H}=10,8771 \text { menit }
$$

Dari hasil perhitungan dengan 10 unit armada didapat kan waktu antara kendaraan sebesar 10,8771 menit, waktu tersebut tidak memenuhi standar Dirjen Perhubungan Darat tahun 2002 yaitu 5-10 menit.

\section{Perconaan 3}

Untuk perbandingan dicoba menggunakan 12 unit armada maka:

$$
\begin{aligned}
& \mathrm{K}=\frac{\mathrm{CTABA}}{\mathrm{HxfA}} \\
& 12=\frac{108,771}{\mathrm{Hx} 100 \%} \\
& \mathrm{H}=\frac{108,771}{12} \\
& \mathrm{H}=9,064 \text { menit }
\end{aligned}
$$

Dari hasil perhitungan dengan 12 unit armada didapat kan waktu antara kendaraan sebesar 9,064 menit, waktu tersebut memenuhi standar Dirjen Perhubungan Darat tahun 2002 yaitu 5-10 menit, tetapi load factor nya hanya 52,26\% tidak memenuhi standar load factor yakni $70 \%$.

Dari tiga kali hasil percobaan didapatkan jumlah bus yang optimal pada trayek pandau- pelita pantai 
sebanyak 11 unit armada dengan waktu tunggu sebesar 10 menit, waktu tersebut memenuhi standar Dirjen Perhubungan Darat tahun 2002 yaitu 5-10 menit.

\section{Kebutuhan armada pada waktu sibuk}

Dari hasil survei jumlah penumpang trans metro pekanbaru pada trayek pandau- pelita pantai didapat jam sibuk dari jam 17.00 sampai 18.00 WIB, jadi didapat lamanya jam sibuk (W) 60 menit.

$\mathrm{K}^{\prime}=\mathrm{K} \times \frac{\mathrm{W}}{\mathrm{CTABA}}$

$K^{\prime}=11 \times \frac{60}{108,771}$

$K^{\prime}=6,06779=7$ Trip kendaraan

\section{Biaya operasional kendaraan}

Biaya pokok atau biaya produksi atau operasional adalah besaran pengorbanan yang dikeluarkan untuk menghasilkan satu satuan unit produksi jasa angkutan. Berdasarkan metode dari Departemen Perhubungan tahun 2002

Tabel 3. Rekapitulasi biaya operasional kendaraan

\begin{tabular}{|c|c|c|c|c|c|c|}
\hline a & HOPQWDBLA & DLIIA B.ED & BLTA BWA-21 & BETL BRSLLI & BALA BEFAD & $\begin{array}{c}\text { Prethe } \\
1\end{array}$ \\
\hline 1 & Bundath & fo. .11993 & if 4tatioliz & io 13543660 & Bo 1492396966 & $35:$ \\
\hline 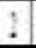 & Entunity & ib $171666^{\circ}$ & Be $\quad 39531410^{\circ}$ & 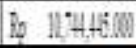 & 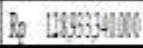 & 86 \\
\hline t & Braprahing & fo 10000 & 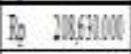 & 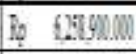 & ho 751580000 & 166 \\
\hline 4 & Seritixil & is 6611 . & is $\quad 311135$ & is $\quad$ solullit & 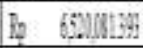 & 1.6 \\
\hline 5 & Gristex & 30 111.15 & 51735 & 811608 & Do y325:4-5 & 10 \\
\hline 6 & 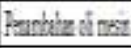 & ib $\quad 1113$ & $665 \%$ & M:7Nom & 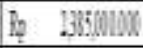 & 05 \\
\hline$i$ & 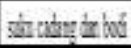 & is $20 \%$ & 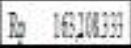 & 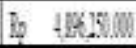 & 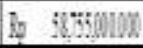 & 13.6 \\
\hline 8 & Guitus & Io 19918 & 50010 & 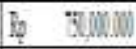 & 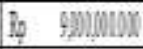 & 10 \\
\hline 9 & Bers:LZ & If $\quad 1.2$ & $17+66$ & HAE: & he latuon & Qt8 \\
\hline 10 & Bandit? & ib 112 & tiul & Ejoun & 9roux & 0.0 \\
\hline
\end{tabular}

(Sumber: Hasil Perhitungan, 2018)

Dari perhitungan setiap biaya, maka di dapat hasil persentase biaya dari biaya yang paling besar hingga biaya yang paling kecil. Pada operasional biaya kendaraan (BOK) bus trans metro pekanbaru trayek 1 pandau - pelita pantai yang paling berpengaruh adalah biaya awak bus yang memiliki persentase $35,31 \%$ atau Rp 2.119,280 per bus/ km.

\section{Pembahasan}

Berdasarkan hasil analisis yang diawali dengan survei pendahuluan pada jam-jam sibuk, dilanjutkan dengan survei yang dilakukan selama 7 (tujuh) hari, dimulai pada hari sabtu tanggal 31 Maret 2018 sampai hari jum'at tanggal 06 April 2018 survei dilakukan dari jam 06.00 WIB sampai jam 19.00 WIB untuk mengumpulkan data primer seperti jumlah penumpang perjam, jarak dari pandau ke pelita pantai, waktu perjalanan dari pandau ke pelita pantai maupun dari pelita pantai ke pandau, dengan jumlah surveyor berjumlah 12 orang untuk 12 bus dengan cara mengikuti bus yang beroperasi pada trayek pandaupelita pantai sekarang ini.

Pada saat menganalisis jumlah bus trans metro pekanbaru yang optimal pada trayek pandau- pelita pantai acuan yang di gunakan adalah Keputusan Direktur Jendral Perhubungan Darat tahun 2002, dengan menggunakan data jumlah penumpang maksimal/jam, jam puncak yaitu pada hari selasa tanggal 03 April 2018 pada pukul 17.00 - 18.00 WIB, dan menggunakan jarak tempuh rata-rata dari pandau ke pelita pantai dan sebaliknya dari pelita pantai ke pandau. Dengan 10 unit armada didapatkan waktu antara kendaraan (headway) sebesar 10,8771 menit, waktu tersebut tidak memenuhi standar Dirjen Perhubungan Darat tahun 2002 yaitu 5-10 menit, kalau menggunakan 11 unit armada untuk trayek pandau-pelita pantai didapatkan waktu antara kendaraan (headway) sebesar 9,934 menit, waktu tersebut memenuhi standar Dirjen Perhubungan Darat tahun 2002 yaitu 5-10 menit, dan menggunakan 12 armada didapat kan waktu antara kendaraan (headway) sebesar 9,064 menit, waktu tersebut memenuhi standar Dirjen Perhubungan Darat tahun 2002 yaitu 5-10 menit, tetapi load factor nya hanya 
$52,26 \%$ tidak memenuhi standar load factor yakni $70 \%$. Jadi didapatkan jumlah bus trans metro pekanbaru trayek pandau- pelita pantai yang optimal 11 unit armada.

Saat ini bus trans metro pekanbaru mengoperasikan 12 unit bus di trayek pandau- pelita pantai, Dari hasil analisis yang dilakukan didapat jumlah bus trans metro pekanbaru yang optimal pada trayek pandaupelita pantai yaitu 11 unit dengan waktu tunggu antara bus 10 menit, waktu tersebut memenuhi standar Dirjen Perhubungan Darat, dari perhitungan biaya operasional kendaraan didapatkan biaya per bus-km Rp. 6.002,16 atau biaya per bus/ tahun yaitu Rp. $450.802 .977,48$.

\section{KESIMPULAN DAN SARAN}

\section{Kesimpulan}

Hasil penegelolahan data menunjukan bahwa jumlah bus trans metro pekanbaru pada trayek pandau- pelita pantai yang optimal sejumlah 11 unit bus setiap harinya dengan waktu tunggu antara kendaraan 10 menit. Hasil ini berbeda dengan fakta yang ada di trayek pandau- pelita pantai yaitu sejumlah 12 unit bus trans metro, berarti belum ada keseimbangan antara permintaan dan supply. Supply bus trans metro pekanbaru trayek pandau pelita pantai yang ada sekarang ini melebihi permintaan yang ada.

Berdasarkan analisis dengan menggunakan Pedoman Teknis Penyelenggaraan Angkutan Penumpang Umum di wilayah Perkotaan Dalam Trayek tetap Dan Teratur, Maka Biaya Operasional Kendaraan (BOK) pada bus trans metro pekanbaru trayek pandau- pelita pantai dengan mengacu pada jumlah kendaraan yang optimal sebanyak 11 unit bus, maka dapat disimpulkan besar biaya operasional kendaraan bus trans metro pekanbaru pada trayek pandau pelita pantai yang dikeluarkan untuk satu bus biaya tiap $\mathrm{km}$ sebesar Rp. 6.002,16 per km, perhari sebesar Rp. 1.252.230,49/ hari, perbulan sebesar Rp. 37.566.914,79/ bulan dan pertahun sebesar Rp. 450.802.977,48 / tahun.

\section{Saran}

Mengacu pada analisis perhitungan yang telah dilakukan dimana pada tahun 2018 jumlah bus trans metro pekanbaru pada trayek pandau- pelita pantai yang optimal 11 unit, maka penulis memberi saran sebagai berikut:

1. Perlu dilakukan penelitian lanjutan untuk mengetahui tariff yang optimal pada trayek pandau- pelita pantai

2. Pemerintah perlu melakukan evaluasi ulang tentang jumlah bus yang beroperasi di trayek pandau- pelita pantai

\section{DAFTAR PUSTAKA}

Dinas Kependudukan dan Catatan Sipil Kota $\begin{array}{ll}\text { Pekanbaru tahun } & 2015\end{array}$ https://www.antarariau.com/berita/55179/disdu kcapil:-laju-pertumbuhan-pendudukpekanbaru-7,43-persen (21 Februari 2018)

Direktorat Jenderal Perhubungan Darat. 2002. Pedoman Teknis Penyelenggaraan Angkutan Penumpang Umum Di Wilaya Perkotaan Dalam Trayek Tetap Dan Teratur. Jakarta: Direktorat Jendral Perhubungan Darat 
Keputusan Menteri Perhubungan Nomor 35 Tahun 2003. Penyelenggaraan Angkutan Orang di Jalan Dengan Kendaraan Umum. Jakarta: Menteri Perhubungan

Keputusan Menteri perhubungan Nomor: KM 65 tahun 1993 Fasilitas Pendukung Kegiatan Lalu Lintas Dan Angkutan Jalan. Jakarta: Menteri Perhubungan

Peraturan Pemerintah Republuk Indonesia Nomor 41 Tahun 1993 Tentang Angkutan Jalan. Jakarta.

Peraturan Pemerintah Republuk Indonesia Nomor 34 Tahun 2006 Tentang Jalan. Jakarta.

Putra.A.A. 2013. Analisis Keseimbangan Jumlah Armada angkutan Umum Berdasarkan Kebutuhan Penumpang. Jurnal Teknik Sipil. Vol. 19 No.1: 1-12.

Rahmawati M. 2009. Penentuan Jumlah Dan Lokasi Halte Rute I Bus Rapid Transit (BRT) Di Surakarta Dengan Model Set Covering Problem. (Tugas Akhir). Surakarta: Program Serjana. Universitas Sebelas Maret.

Tamin O.Z. 2000. Perencanaan dan Permodelan Transportasi, Bandung: Institut Teknologi Bandung

Warpani 1990 Merencanakan Sistem Perangkutan. Bandung: Institut Teknologi Bandung

Winaya A. 2017. Analisis Kebutuhan Jumlah Armada Angkutan Umum Trayek Terminal BenowoKalimas Barat (Lyn BJ) Kota Surabaya. Jurnal Teknik Sipil. Vol. 2 No.1: 1-3.

Yuniarti T. 2009. Analisis Tariff Angkutan unum Berdasarkan Biaya Operasional Kendaraan Ability To Paydan Willingness To Pay.
(Skripsi). Surakarta: Program Serjana. Universitas Sebelas Maret. 